\title{
Investigating the effects of interprofessional communication education for medical students
}

\author{
Seung Jae Kim¹,2 Oh Deog Kwon ${ }^{3}$, Kyae Hyung Kim², Ji Eun Lee ${ }^{5}$, Seung-Hee Lee', Jwa-Seop Shin \\ and Sang Min Park ${ }^{4,6}$ \\ ${ }^{1}$ Department of Medical Education, Seoul National University College of Medicine, ${ }^{2}$ Department of Family Medicine, \\ Seoul St. Mary's Hospital, College of Medicine, The Catholic University of Korea, Seoul, ${ }^{3}$ Navy Medical Office, \\ ROK Submarine Force Command, Changwon, ${ }^{4}$ Department of Family Medicine, Seoul National University Hospital, \\ Seoul, ${ }^{5}$ Department of Family Medicine, CHA Bundang Medical Center, CHA University, Seongnam, and ${ }^{6}$ Department \\ of Family Medicine, Seoul National University College of Medicine, Seoul, Korea
}

Purpose: Interprofessional communication skills are an essential competency for medical students training to be physicians. Nevertheless, interprofessional education (IPE) is relatively rare in Korean medical schools compared with those overseas. We attempted to evaluate the effectiveness of the first IPE program in our school.

Methods: In the first semester of the school year 2018, third-grade medical students ( $N=149)$ at the Seoul National University College of Medicine participated in 'communication between healthcare professionals in the clinical field' training, which consisted of small group discussions and role-play. To evaluate the effectiveness of this training, we conducted pre- and post-training questionnaire surveys. Comparing paired t-tests, we evaluated the students' competency in interpersonal communication and their attitude towards the importance of IPE before and after the training. The Global Interpersonal Communication Competence Scale (GICC-15) was used to evaluate competency in interpersonal communication.

Results: Out of 149 students, 144 completed the pre- and post-training questionnaires. The total GICC-15 scores before and after training were $55.60 \pm 6.94$ (mean \pm standard deviation) and $58.89 \pm 7.34$, respectively $(p=0.000$ ). All subcategory scores of GICC-15 after training were higher after training and were statistically significant $(p<0.05)$, except for two subcategories. The importance of IPE score also improved after training but was not significant $(p=0.159)$. The appropriateness of content and training method scores were $3.99 \pm 0.92$ and $3.94 \pm 1.00$, respectively.

Conclusion: From the results, our school's IPE program demonstrated a positive overall educational effect. Deployment of systematic and varied IPE courses is expected in the future, with more longitudinal evaluation of educational effect.

Key Words: Medical students, Communication, Interprofessional relations, Role playing, Small group discussion

\section{Introduction}

Cooperation and effective communication between physicians, nurses, and other health care workers in a clinical setting is essential to ensure patient safety and restore health [1]. According to the Joint Commission, a nonprofit corporation that evaluates US medical institutions, one of the most common causes of hospital redlight incidents from 1995 to 2006 was the lack of com-
Received: February 8, 2019 • Revised: March 28, 2019 • Accepted: April 18, 2019 Corresponding Author: Jwa-Seop Shin (https://orcid.org/0000-0002-6251-3616) Department of Medical Education, Seoul National University College of Medicine, 103 Daehak-ro, Jongno-gu, Seoul 03080, Korea

Tel: +82.2.740.8175 Fax: +82.2.741.1186 email: hismed1@snu.ac.kr

Corresponding Author: Sang Min Park (https://orcid.org/0000-0002-7498-4829)

Department of Family Medicine, Seoul National University Hospital, 101 Daehak-ro, Jongno-gu, Seoul 03080, Korea

Tel: +82.2.2072.3331 Fax: +82.2.766.3276 email: smpark.snuh@gmail.com
Korean J Med Educ 2019 Jun; 31(2): 135-145.

https://doi.org/10.3946/kjme.2019.125

eISSN: 2005-7288

(C) The Korean Society of Medical Education. All rights reserved. This is an open-access article distributed under the terms of the Creative Commons Attribution Non-Commercial License (http:// creativecommons.org/licenses/by-nc/3.0/), which permits unrestricted non-commercial use, distribution, and reproduction in any medium, provided the original work is properly cited. 
munication between health care professionals [2]. In addition, a healthcare study conducted on 28 hospitals in Australia found that approximately $11 \%$ of preventable medical accidents that occurred in hospitals were due to communication problems [3]. Nevertheless, conflicts among healthcare professionals in hospitals are increasing. A study on this subject at the Seoul National University Hospital revealed that more than $80 \%$ of residents, nurses, and other healthcare providers reported experiencing friction with their peers more than once a year [4]. In addition, a study of doctors and nurses at three university hospitals in Seoul found that $76.6 \%$ of the doctors and $96.7 \%$ of the nurses had experienced at least one interprofessional conflict at their workplace [5]. Conflicts among healthcare professionals dealing with patients' lives can be detrimental to the efficiency of their work and can interfere with important medical decisions, ultimately harming patients [6]. As a result, there is an emphasis on the importance of interprofessional communication skills as one of the most essential competencies for clinical doctors who treat patients. In the United States, Greer et al. [7] conducted a questionnaire survey of 127 contacts at 68 universities across 31 states and the District of Columbia, and found that $85 \%$ of respondents replied that they had an interprofessional education (IPE) course at their school. In addition, studies evaluating the effects of IPE on medical and nursing college students have shown that their level of communication competency and cooperation have increased after taking IPE courses [8,9]. For Korean medical schools, the interest in communication education in the medical education curriculum has increased over the last 10 years. In many Korean medical schools, medical communication skills are taught as part of the 'patient-doctor-society' or 'introduction to clinical medicine' classes [10-12]. According to previous Korean studies on the effects of medical communication edu- cation, medical students' interest and competency in appropriate communication skills, as well as their perception of the necessity of communication education, increased after communication classes [10,13-15]. However, most of the communication education in Korean medical schools has been limited to communicating with patients, such as patient interview skills, and with little IPE $[5,12,16]$. Therefore, as well as communication education between patient and doctor, education regarding communication between medical personnel is also deemed necessary in Korean medical schools. The purpose of this study was to evaluate the effectiveness of communication education among healthcare professionals through small group role-play and discussions, and to compare the change in students' perception and skills in interprofessional communication before and after training. In addition, we endeavor to advocate the necessity of IPE and its inclusion in the regular curriculum of Korean medical schools based on the results of this study.

\section{Methods}

\section{Concept of IPE used in this study}

According to the United Kingdom Center for $\mathrm{Ad}^{-}$ vancement in Interprofessional Education, IPE occurs when two or more professions learn with, from and about each other to improve collaboration and the quality of patient care [17]. According to this definition, our training program is not a complete IPE because the students majoring in other professions did not participate together. Harden, however, presented the IPE as a continuous spectrum of 11 steps from isolated learning from a single discipline (Isolation) to integrated learning across disciplines (Transprofessional education) [18]. 
Therefore, our program can be considered as 'isolation' phase which is the earliest stage of IPE according to Harden [18]. In addition, Canadian Interprofessional Health Collaborative presented role clarification, team functioning, patient/client/family/community centered care, collaborative leadership, interprofessional communication, and interprofessional conflict resolution as IPE competency framework [19]. Our IPE program was focused on interprofessional communication and conflict resolution among these items.

\section{Study subjects}

This study examined 149 students in the third grade of Seoul National University College of Medicine in the school year 2018. Interprofessional communication training was conducted as a part of the "humansociety-medicine 5 class in the first semester. The students were just 3 months into clinical rotation program at the time of this training. The title of the training session was 'communication between healthcare professionals in the clinical field.' The educational goals of this training were to enable our students to identify the characteristics and problems of the conversational style of themselves and acquire various communication skills which lead to positive interpersonal relationships with other healthcare providers by experiencing the interpersonal conflict situations. The training was conducted for a total of 3 hours and consisted of small group role-play, small group discussions and presentations, and an overall presentation and discussion for the whole class. One hundred and forty-nine students were randomly assigned to 12 small groups of 12-13 students. Six group discussion rooms were arranged for students, with two groups sharing each room for their small group discussions. We presented two cases of conflicts between healthcare professionals to the students. One case was a conflict between an intern and a resident, and the other was a conflict between a resident and a nurse (Supplement 1). Each group selected one case to conduct a roleplaying and video-recording exercise. In order to do this, each group selected a leader, actors for role- play, video photographers, and presenters. Half the groups were asked to role-play and film a good example of conflict resolution for their selected case, and the other half were asked to demonstrate a bad example of conflict resolution. The cases of conflict were developed by four professors, one from the department of medical education and three from the department of family medicine. For each small group discussion room, one supervisor facilitated the group practice and discussion. These six facilitators consisted of three clinical fellows and three residents from Seoul National University Hospital's department of family medicine. After the role-play and video recording, the students filled out a worksheet evaluating the communication skills of the performers. Groups that worked on the good example of conflict resolution discussed with the facilitator the positive points of communication and how it could have been improved. The groups that worked on the bad example of conflict resolution discussed the communication problem and how it could have been improved. The facilitators then selected one group that performed better than the other in each room, and showed their video recordings in a final presentation to all students, facilitators, and the professor in charge of the subject, before a final collective discussion (Supplement 2). This study was approved by the institutional review board of the Seoul National University Hospital (IRB approval no., C-1808-143-967) and informed consent was waived.

\section{Evaluation of educational effectiveness}

We used Kirkpatrick's 4-level evaluation model to evaluate the effectiveness of our interprofessional communication training program. Kirkpatrick's 4-level 
model consists of reaction, learning, behavior, and results. Our evaluation was limited to the reaction and learning stages, which can be evaluated immediately after the training. First, the evaluation of the reaction stage was conducted through questionnaires in order to determine whether the contents and methods of the training program were appropriate. Then, in the evaluation of the learning stage, we compared the change in attitude and overall communication competency of students before and after the training. The questionnaire used to evaluate the attitude change in students asked the importance of interprofessional communication training for future clinical doctors. The evaluation of students' competency in interprofessional communication before and after practice was conducted using the Global Interpersonal Communication Competence Scale (GICC15). GICC-15 is a translated and modified version of Interpersonal Communication Competence Scale of Rubin and Martin [20] by Hur [21] to match Korean circumstances. Although there are many tools to evaluate the communication competency of healthcare professionals, those were mostly tools that evaluated the competency of physicians' communication with the patients. Thus, we selected GICC-15 because our training was focused on communication skills in conflicts between healthcare professionals, rather than patienttreating situations. In fact, GICC-15 has been used in many previous studies as a measure of communication in interpersonal relationships among healthcare providers [22-25]. Therefore, we thought that GICC-15, which includes various subcategories that enable to evaluate diverse aspects of individual's interpersonal conversation skills, was suitable as a measurement tool for our study. This questionnaire consists of 15 sub-factors that assess communication ability, and each factor consists of one question, making a total of 15 questions. The subcategories of GICC-15 were specifically 'self-disclosure, 'empathy,' 'social relaxation,' 'assertiveness,' 'concentration,' 'interaction management,' 'expressiveness,' 'supportiveness,' 'immediacy,' 'efficiency,' 'social appropriateness,' 'conversational coherence,' 'goal detection,' 'responsiveness,' and 'noise control.' In order to improve the suitability of this study tool, we revised the subfactors and questions, altering the expression of the items such that they would reflect the supervision of the professors of the medical education and family medicine departments. For example, in the case of the "concentration' sub-factor, the corresponding question was "I focused on the speaker's words." We replaced 'concentration' with 'reflective listening' on the worksheet to make it easier for students to understand what concentration meant within the context of communication skills. The GICC-15 was found to have a reliability of 0.72 for the Cronbach's $\alpha$ coefficient in the study of Hur [21]. In this study, Cronbach's Alpha scores of GICC-15 for pre $^{-}$and post-training were 0.85 and 0.87 , respectively. Every question in the pre- and post-practice questionnaires were rated on a 5-point Likert scale (1 point, strongly disagree; 2 point, disagree; 3 point, neutral; 4 point, agree; 5 point, strongly agree) (Supplements 3-5).

\section{Statistical analysis}

The pre- ${ }^{-}$and post-practice questionnaires were computerized using Google Forms (Google Inc., Mountain View, USA). In order to compare the students' communication skills and perceptions before and after practice, the total mean score and the mean scores by subcategory were compared by paired t-test. All statistical analysis was performed using STATA ver. 14.0 (Stata Corp., College Station, USA), and a p-value of 0.05 or less was defined as statistically significant. 


\section{Results}

The reliability of the pre- and post-questionnaires used in this study was measured based on their results. The Cronbach's $\alpha$ coefficient was 0.85 in the prequestionnaire (16 questions), and 0.89 in the postquestionnaire (18 questions), showing that they both had relatively high reliability.

\section{Baseline characteristics}

A statistical analysis was conducted on 144 of 149 available students who participated in the practice. Five students who did not complete all the questions in the pre- and post-practice questionnaires were excluded from the analysis. The mean age of the subjects was $24.07 \pm 1.89$ years (mean \pm standard deviation [SD]). Of the 144 subjects, 91 were men $(63.2 \%)$ and 53 were women (36.8\%). When classified according to admission type, 85 of 144 (59.0\%) were admitted by the premedical department, and the other 59 (41\%) were admitted via transfer (Table 1).

Table 1. Baseline Characteristics ( $N=144)$

\begin{tabular}{llc}
\hline \multicolumn{1}{c}{ Characteristic } & \multicolumn{1}{c}{ Category } & Value \\
\hline Age $(y r)$ & & $24.07 \pm 1.89$ \\
Sex & Men & $91(63.2)$ \\
& Women & $53(36.8)$ \\
Admission type & Premedical & $85(59.0)$ \\
& Transfer & $59(41.0)$ \\
\hline
\end{tabular}

Data are presented as mean \pm standard deviation or number of subjects $|\%|$.

\section{Comparison of communication competence scores before and after practice}

We compared the total scores of all 15 questions of GICC-15 for both pre- and post-practice questionnaires for each student. The total mean score of the students before practice was $55.60 \pm 6.94$ points (mean \pm SD) out of a potential 75 , and the total mean score after practice was $58.89 \pm 7.34$, showing that students' overall communication competency was higher after practice. These results were also statistically significant $(\mathrm{p}=0.000)$ (Table 2). When compared, the 15 post-practice scores of the GICC-15 subcategories were all higher than the prepractice scores. All of these subcategory scores were statistically significant, except for the subcategory number 5 that evaluates 'reflective listening,' and subcategory number 14 that evaluates 'responsiveness.' The subcategories with the highest mean scores before the practice were 'responsiveness' ( $4.27 \pm 0.65$ points), 'reflective listening" (4.11 \pm 0.71 points), and "supportiveness' ( $4.10 \pm 0.74$ points). The subcategories with the lowest average scores before the practice were 'conversational appropriateness' ( $2.33 \pm 0.99$ points), 'assertiveness' (3.37 \pm 0.95 points), and 'social relaxation' (3.47 \pm 0.97 points). The subcategory which showed the greatest increase in average score was 'efficiency' with a 0.46 point increase. The 'conversational coherence' and 'immediacy' subcategories showed a relatively high increase rate with 0.36 and 0.31 point increases, respectively (Table 3).

Table 2. Total GICC Scores Comparison between before and after Training $(N=144)$

\begin{tabular}{ccccc}
\hline & Before & After & T-score & p-value $^{\text {a) }}$ \\
\hline Total GICC-15 score & $55.60 \pm 6.94$ & $58.89 \pm 7.34$ & -6.96 & 0.000 \\
\hline
\end{tabular}

Data are presented as mean \pm standard deviation.

GICC: Global Interpersonal Communication Competence Scale.

${ }^{a)}$-value $<0.05$ was defined as statistically significant. 
Table 3. GICC Scores Comparison between before and after Training by Subcategory (N=144)

\begin{tabular}{lcccc}
\hline \multicolumn{1}{c}{ Subcategory } & \multicolumn{2}{c}{ GICC score } & T-score & p-value $^{\text {al }}$ \\
\cline { 2 - 3 } 1. Self disclosure & Before & After & -2.98 & 0.003 \\
2. Empathy & $3.63 \pm 0.95$ & $3.85 \pm 0.85$ & -2.99 & 0.003 \\
3. Social relaxation & $4.03 \pm 0.69$ & $4.22 \pm 0.63$ & -4.32 & 0.000 \\
4. Assertiveness & $3.47 \pm 0.97$ & $3.76 \pm 0.92$ & -3.23 & 0.002 \\
5. Reflective listening & $3.37 \pm 3.60$ & $3.60 \pm 0.93$ & -1.91 & 0.059 \\
6. Interaction management & $4.11 \pm 0.71$ & $4.22 \pm 0.65$ & -2.54 & 0.012 \\
7. Expressiveness & $3.83 \pm 0.79$ & $3.99 \pm 0.75$ & -3.33 & 0.001 \\
8. Supportiveness & $3.67 \pm 1.00$ & $3.94 \pm 0.92$ & -2.61 & 0.010 \\
9. Immediacy & $4.10 \pm 0.74$ & $4.26 \pm 0.71$ & -4.60 & 0.000 \\
10. Efficiency & $3.68 \pm 0.85$ & $3.99 \pm 0.80$ & -6.37 & 0.000 \\
11. Social appropriateness & $3.49 \pm 0.82$ & $3.95 \pm 0.76$ & -2.93 & 0.004 \\
12. Conversational coherence & $3.90 \pm 0.71$ & $4.06 \pm 0.75$ & -3.80 & 0.000 \\
13. Goal detection & $2.33 \pm 0.99$ & $2.69 \pm 1.19$ & -2.78 & 0.006 \\
14. Responsiveness & $3.90 \pm 0.80$ & $4.06 \pm 0.76$ & -0.25 & 0.807 \\
15. Noise control & $4.27 \pm 0.65$ & $4.28 \pm 0.63$ & -2.94 & 0.004 \\
\hline
\end{tabular}

Data are presented as mean \pm standard deviation.

GICC: Global Interpersonal Communication Competence Scale.

${ }^{a)} p$-value $<0.05$ was defined as statistically significant.

\begin{tabular}{lccc}
\hline Table 4. Importance of Communication Score Comparison between before and after Training $(\mathrm{N}=144)$ & \\
\hline Importance of communication education & Mean score \pm standard deviation & T-score & p-value \\
\hline Before & $4.17 \pm 0.97$ & -1.42 & 0.159 \\
After & $4.27 \pm 0.88$ & & \\
\hline
\end{tabular}

${ }^{a}$ p-value $<0.05$ was defined as statistically significant.

\section{Comparison of importance and appro- priateness of class scores}

For the question "how important do you think this class is for you when working as clinical doctor in the future," the mean score before practice was $4.17 \pm 0.97$ points (mean $\pm \mathrm{SD}$ ), and the mean score after practice was $4.27 \pm 0.88$ points. Although the mean score slightly increased by 0.1 points after practice, it was not statistically significant $(\mathrm{p}=0.159)$ (Table 4$)$. The postpractice questionnaire contained two extra questions regarding whether the content of the class and methods used were appropriate, in order to evaluate the overall satisfaction of training. The mean scores were 3.99 \pm 0.92 points for the suitability of content and 3.94 1.00 for the suitability of methods used in class.

\section{Discussion}

The results of this study revealed that the average score of all items regarding the competency and perceived importance of communication were improved after the training. The score differences were statistically significant, excepting those of three questions. This suggests that the training had a positive overall educational effect for students. Previous Korean studies assessing educational effect by conducting pre- and post-evaluation of the communication class have found similar results, though not with regard to IPE [13-15,22]. In addition, overseas studies that examined the effects of IPE also confirmed the positive effect of training; however, these studies did not demonstrate pre- and 
post-evaluation of IPE [8,9].

In this study, interprofessional communication training was carried out through the autonomous role-play of medical students, rather than by conventional lecture. Role-play is known to be a pedagogy that not only fosters students' skills, but also enables them to feel empathy for each role, thereby enhancing learning effectiveness [26]. In fact, Knowles et al. [27] found that students who received lectures, patient interviews, roleplaying, video recording, and feedback had higher objective structured clinical examination scores compared with students who received only lectures.

Students in our study had small group discussions about how the person who performed the role-play could improve their communication, and how to solve the conflict between healthcare professionals in the cases they received. A study investigating the relationship between the amount of small group discussion and students' moral reasoning skills in medical ethics education by Self et al. [28] found that students who had more small group discussions demonstrated significantly increased moral reasoning skills.

In the post-training questionnaire, our students rated an average of $3.94 \pm 1.00$ (mean \pm SD) points for the question regarding the suitability of the teachinglearning methods used, indicating that they were generally satisfied with the teaching methods. Therefore, our results suggest that the adoption of role-play and small group discussion as the main teaching methods in training contributed to maximizing the educational effect.

Moreover, we performed IPE for third-grade medical students who had just started clinical rotation for the study. There have been some controversies over the timing of introducing IPE to students in terms of gaining educational effectiveness. Some emphasize that early learning of IPE for students may reduce not only the stereotypes of their own profession but also professions of others [29]. On the other hand, Pirrie et al. [30] suggests that it is more effective to introduce IPE after students gain clear understanding of their professional roles in the clinical setting. We decided that it is appropriate for students to start training before developing stereotypes about different professions since our training was aimed at acquiring appropriate communication skills to build a decent interpersonal relationships with other healthcare providers. Therefore, the training was conducted for the third-grade students who were just into the clinical rotation program. Ker et al. [31] emphasized the importance of early introduction of IPE by confirming the positive educational effects of collaborative clinical practice in a simulated environment with second-year undergraduate students of medical and nursing schools. We also confirmed that third-grade students of our school's GICC-15 scores and attitude score of how important they think of this training for them to work as a clinical doctor in the future were all higher after training than before, though some items were not statistically significant. In this respect, we can cautiously say that our intended educational goals were attained in some extent.

Our study is significant because we evaluated the effects of IPE, which has, to this day, rarely been implemented in Korean medical schools, by comparing pre- and post-practice evaluations. Although medical communication education has been actively conducted at medical schools in Korea, the focus of this education is limited to interviews between doctors and patients $[12,16]$. A previous Korean study on the effects of communication education did partially include the communication between healthcare professionals, but did not include pre- and post-evaluation of IPE [10]. Therefore, the results of our study could be taken as evidence to suggest the necessity of introducing IPE 
officially in the curriculum of medical schools in Korea. This study has a limitation in that educational effects were evaluated after only 3 hours of education, which is a relatively short time-period. Thus, although most results of this study are statistically significant, it is still unclear whether this can lead to practical significance. In order to obtain more reliable results, it would have been more effective to evaluate the educational effect after a longer-term communication education rather than after a single event. Therefore, it is necessary to examine the effectiveness by introducing more diverse and systematic IPE programs. Nevertheless, this limitation also can be interpreted in a positive way that communication skills can be improved to some extent by a short period of education.

In addition to education time constraints, there were constraints on arranging training space and a workforce to act as facilitators. These constraints forced us to assign a relatively large number of students (12-13) per group. Ultimately, some students in the groups could not perform the role-play themselves, but watched their teammates perform instead. Additionally, each group could address only one of two available conflict cases, and they also could only practice either the good or bad example of conflict solution for the selected case. In order to overcome these limitations, we placed two groups in each group discussion room, and presented different conflict cases to groups in the same room, to enable all groups to experience both cases. Furthermore, after the small group discussions, we gathered all students together to watch and discuss the selected role-play videos from each room, in order to maximize the educational effect in these limited circumstances. Of course, it would have been more effective if all students had been given the opportunity to take part in role-play with various cases and solutions without any constraints. However, considering the fact that these administrative constraints were inevitable and expected for the first time IPE has been applied in our medical school, we believe our research could contribute to provide a basis for the development of a more systematic IPE program in the near future for our school and for other medical schools of Korea.

In the overseas, IPE addresses not only interprofessional communication and conflict resolution, but also collaborative team-working when treating patients in critical situations (e.g., surgery, cardiopulmonary resuscitation). Various training methods are used to this effect, such as direct role-play and simulation exercises, and education is conducted with students taking different majors, including those studying at nursing schools [8,9,32-34]. Our school is also preparing a curriculum for future IPE that will be conducted jointly with nursing schools on various topics.

In conclusion, our medical school's trial of 'communication between healthcare providers in the clinical field' training for third-grade medical students demonstrated positive educational effects. We expect to expand our IPE program to include effective collaboration among healthcare professionals when a patient is in a critical situation, and to actually learn with students majoring in other healthcare fields just as medical schools overseas include in their IPE. It is necessary to conduct further longitudinal studies on the effect of IPE after its introduction as part of a systematic curriculum organized by grade or semester for students. In addition, it would be useful to examine how IPE experienced at medical school affects the performance of students in their work as clinical doctors in the future.

\section{Supplementary Materials}

Supplementary files are available from https://doi.org/ 10.3946/kjme.2019.125. 
Supplement 1. Cases of Conflict between Healthcare Professionals.

Supplement 2. Timetable of 'Communication between Healthcare Professionals in the Clinical Field'.

Supplement 3. Worksheet of 'Communication between Healthcare Professionals in the Clinical Field'.

Supplement 4. Pre-training Questionnaire Survey of 'Communication between Healthcare Professionals in the Clinical Field'.

Supplement 5. Post-training Questionnaire Survey of 'Communication between Healthcare Professionals in the Clinical Field'.

\section{ORCID:}

Seung Jae Kim: https://orcid.org/0000-0001-8885-7137; Oh Deog Kwon: https://orcid.org/0000-0002-6162-0348; Kyae Hyung Kim: https://orcid.org/0000-0001-9954-6422; Ji Eun Lee: https://orcid.org/0000-0003-3171-1713; Seung-Hee Lee: https://orcid.org/0000-0001-8672-5253; Jwa-Seop Shin: https://orcid.org/0000-0002-6251-3616; Sang Min Park: https://orcid.org/0000-0002-7498-4829

Acknowledgements: None.

Funding: No funding was obtained for this study.

Conflicts of interest: No potential conflict of interest relevant to this article was reported.

Author contributions: Conception or design of the work: SJK, JSS, SMP; data collection, data analysis, and interpretation: SJK, ODK; and drafting the article, critical revision of the article, and final approval of the version to be published: SJK, KHK, JEL, SHL, JSS, SMP.

\section{References}

1. Oza SK, Wamsley M, Boscardin CK, Batt J, Hauer KE. Medical students' engagement in interprofessional collaborative communication during an interprofessional observed structured clinical examination: a qualitative study. J Interprof Educ Pract. 2017;7:21-27.

2. Lee JY. Effective communication for patient safety. J Korean Med Assoc. 2015;58(2):100-104.

3. Wilson RM, Runciman WB, Gibberd RW, Harrison BT, Newby L, Hamilton JD. The quality in Australian health care study. Med J Aust. 1995;163(9):458-471.

4. Choi KJ, Choi EK, Hong JH, et al. A questionnaire study on conflict between healthcare professionals for teaching students in Seoul National University College of Medicine. J Korean Bioeth Assoc. 2008;9(2):17-34.

5. Lee YH, Ahn D, Moon J, Han K. Perception of interprofessional conflicts and interprofessional education by doctors and nurses. Korean J Med Educ. 2014;26(4): 257-264.

6. Lee JW, Bak YI, Baek SJ, Lee JU, Lee HY, Jeoung YO. How hospital nurses communicate with physician. J Humanit. 2014; 71(1):345-385.

7. Greer AG, Clay M, Blue A, Evans CH, Garr D. The status of interprofessional education and interprofessional prevention education in academic health centers: a national baseline study. Acad Med. 2014;89(5):799-805.

8. Keller KB, Eggenberger TL, Belkowitz J, Sarsekeyeva M, Zito AR. Implementing successful interprofessional communication opportunities in health care education: a qualitative analysis. Int J Med Educ. 2013;4:253-259.

9. Balogun SA, Rose K, Thomas S, Owen J, Brashers V. Innovative interprofessional geriatric education for medical and nursing students: focus on transitions in care. QJM. 2015;108(6):465-471.

10. Lee YM, Oh YJ, Ahn DS, Yoon SM. Implementing a communication skills course for undergraduate medical students. Korean J Med Educ. 2007;19(2):171-175.

11. Lee YH, Lee YM. Development of a patient-doctor communication skills model for medical students. Korean J Med Educ. 2010;22(3):185-195. 
12. Lee I, Kim CS, Lee HS, Lee WS. A content analysis on a form and manner in medical communication subject: focused on the medical schools in Korea. Commun Theor. 2015;11(2):104-141.

13. Kim S, Lee SJ, Choi CJ, Hur Y. The effectiveness of communication skills of pre-medical students. Korean J Med Educ. 2006;18(2):171-182.

14. Lihm HS, Kim HY, Choi JS. The effectiveness of medical communication skill of medical students, through an emphasis on role play. Kosin Med J. 2012;27(2):151159.

15. Kim HJ, Park EH, Kim DH. Medical students' change of thought after a two year course on medical interview skills. Korean J Med Educ. 2002;14(2):165-174.

16. Park EW. Development of medical communication subject in medical school curriculum. Korean J Health Commun. 2009;4(4):23-33.

17. Barr H. Interprofessional education: today, yesterday and tomorrow: a review, 2002. London, UK: Higher Education Academy, Health Sciences and Practice Network; 2002.

18. Harden RM. AMEE guide no. 12: multiprofessional education: part l-effective multiprofessional education: a three-dimensional perspective. Med Teach. 1998;20(5): 402-408.

19. Orchard C, Bainbridge L, Bassendowski S, et al. A national interprofessional competency framework. Vancouver, Canada: Canadian Interprofessional Health Collaborative; 2010.

20. Rubin RB, Martin MM. Development of a measure of interpersonal communication competence. Commun Res Rep. 1994;11(1):33-44.

21. Hur GH. Construction and validation of a global interpersonal communication competence scale. Korean J Journal Commun Stud. 2003;47(6):380-408.

22. Lee MR, Kwag YK. The effects of nursing communication curriculum. Asia Pac J Multimed Serv Converg Art
Humanit Sociol. 2016;6(4):181-190.

23. Joo GE, Sohng KY, Kim HJ. Effects of a standardized patient simulation program for nursing students on nursing competence, communication skill, self-efficacy and critical thinking ability for blood transfusion. J Korean Acad Fundam Nurs. 2015;22(1):49-58.

24. Yang YK. Mediating effect of communication skill in the relationship between fatigue and clinical practice stress in nursing students. J Korean Acad Fundam Nurs. 2018; 25(1):58-67.

25. Hyun MS, Cho HJ, Lee MA. Effect of SBAR-collaborative communication program on the nurses' communication skills and the collaboration between nurses and doctors. J Korean Acad Nurs Adm. 2016;22(5):518-530.

26. Kuipers JC, Clemens DL. Do I dare?: using role-play as a teaching strategy. J Psychosoc Nurs Ment Health Serv. 1998;36(7):12-17.

27. Knowles C, Kinchington F, Erwin J, Peters B. A randomised controlled trial of the effectiveness of combining video role play with traditional methods of delivering undergraduate medical education. Sex Transm Infect. 2001;77(5):376-380.

28. Self DJ, Olivarez M, Baldwin DC Jr. The amount of small-group case-study discussion needed to improve moral reasoning skills of medical students. Acad Med. 1998;73(5):521-523.

29. Horder J. The centre for advancement of interprofessional education. Educ Health. 1996;9(3):397-400.

30. Pirrie A, Wilson V, Elsegood J, et al. Evaluating multidisciplinary education in health care. Edinburgh, UK: Scottish Council for Research in Education; 1998.

31. Ker J, Mole L, Bradley P. Early introduction to interprofessional learning: a simulated ward environment. Med Educ. 2003;37(3):248-255.

32. West C, Graham L, Palmer RT, et al. Implementation of interprofessional education (IPE) in 16 US medical schools: common practices, barriers and facilitators. J 
Interprof Educ Pract. 2016;4:41-49.

33. Blue AV, Zoller J, Stratton TD, Elam CL, Gilbert J. Interprofessional education in US medical schools. J Interprof Care. 2010;24(2):204-206.
34. Wagner J, Liston B, Miller J. Developing interprofessional communication skills. Teach Learn Nurs. 2011;6(3):97-101. 